\title{
O "NOVO" CPC E A OPORTUNIDADE DESPERDIÇADA
}

\author{
Cláudia Galiberne Ferreira' \\ Romano José Enzweiler²
}

Resumo: Encontra-se em tramitação no Congresso Nacional o projeto do "novo" CPC, em sua enésima versão. Já quando de sua apresentação inicial, no Senado da República, mostrava-se o texto carente de sentido e direção. Agora, "mutilado" e "enxertado" por todos os lados, desidratado de cientificidade e utilidade como resultado de longa negociação política, refém do acaso e do descuido, resume-se a alguns poucos avanços e tantos e inexplicáveis retrocessos. Nesta breve reflexão, apresentamos a estrutura inicial do projeto do "novo" CPC, as principais motivações (diretrizes) utilizadas pela comissão inicial formada no Senado da República, os cinco objetivos por ela elencados, o diálogo havido entre a Constituição Federal e o Código de Ritos para, então, pontuar os seus mais graves problemas a partir da perspectiva de quem opera no dia a dia do f'órum, como Juiz de Direito e como Advogada, concluindo tratar-se de uma rara oportunidade desperdiçada.

Palavras-chave: Novo CPC. Reforma. Disfuncionalidade. Anacronismo. Oportunidade desperdiçada.

\section{INTRODUÇÃO}

a) $\mathrm{O}$ novo CPC e a Comissão Especial

A Comissão Especial da Câmara dos Deputados aprovou, dia 17 deste mês de julho, a redação final do Projeto de Lei n.

1 Advogada em Santa Catarina, Especialista em Direito Processual Civil. E-mail: romanoenzweiler@tjsc.jus.br

2 Juiz de Direito em Santa Catarina, Mestre em Relações Econômicas e Sociais Internacionais pela Uminho, Portugal. E-mail: romanoenzweiler@tjsc.jus.br 
8.046/2010, que institui o "novo" Código de Processo Civil. Agora, segundo notícias do parlamento, o projeto seguirá a plenário e deverá ser votado no início do mês de agosto.

O texto daí tirado conseguiu ser ainda mais decepcionante, por seu surpreendente anacronismo e disfuncionalidade, do que aquele saído do Senado e encaminhado à Câmara dos Deputados, tempos atrás.

Apenas para se ter uma ideia do que virá por aí, o "novo" (?) CPC ressuscitou a separação judicial, que tristemente insiste em permanecer no Código Civil de 2002. Figura canhestra e desbotada, sem qualquer sentido prático sincero na vida das pessoas de bem, foi em boa hora banida pela emenda constitucional $n$. $66 / 2010$, mas mantida por parte da doutrina em seus manuais escolares sob os argumentos mais excêntricos, com o objetivo de utilizar-se, quando conveniente, das suas estranhas espécies - separação "remédio" e separação "sanção" -, para punição, por exemplo, do cônjuge adúltero (?), figura penal tardiamente varrida do Código Penal no ano de 2005.

Enfim, seremos presenteados com um Código que se intitula "novo", mas que se mostra na verdade mumificado, que nada ou quase nada servirá para a melhoria dos serviços de justiça, como se demonstrará a seguir.

\section{b) A estrutura proposta}

O "novo" código contém, em sua "enésima" versão, além das tradicionais "disposições finais e transitórias" (agora denominadas como Livro Complementar das Disposições Finais e Transitórias), Partes Geral e Especial, possuindo os seguintes livros, a saber:

Parte Geral:

Livro I - Das normas processuais civis

Livro II - Da função jurisdicional

Livro III - Dos sujeitos do processo

Livro IV - Dos atos processuais 
Livro V - Da tutela antecipada

Livro VI - Da formação, suspensão e extinção do processo

Parte Especial:

Livro I - Do Processo de conhecimento e do cumprimento de sentença

Livro II - Do processo de execução

Livro III - Dos processos nos tribunais e dos meios de impugnação das decisões judiciais

Uma das novidades, no que respeita à organização do CPC, fica por conta da inserção de uma Parte Geral (Livro I), na qual se incluíram (ou se referem), além de outros temas, os princípios constitucionais e regras gerais aplicáveis ao funcionamento de todo o sistema processual civil.

\section{AS PRINCIPAIS MOTIVAÇÕES DA COMISSÃO PARA FEITURA DO NOVO CPC: AGILIDADE, SIMPLICIDADE E EFETIVIDADE DO RESULTADO DAAÇÃO (RESOLVER PROBLEMAS)}

O núcleo da reforma proposta pela Comissão de juristas reside na decantada morosidade do Poder Judiciário.

Pretende o novo código proporcionar ao país uma "Justiça mais rápida e, naturalmente, mais efetiva", através de um texto de linguagem simples, como simplificada imaginam a própria ação processual.

"Resolver problemas". Esta, conforme a Comissão, uma das linhas principais do trabalho ali desenvolvido. "Deixar de ver o processo como teoria descomprometida de sua natureza fundamental de método de resolução de conflitos, por meio do qual se realizam valores constitucionais". Este o mote utilizado.

Portanto, "celeridade"-"efetividade" é o binômio que permeia toda a novel compilação, almejando o novo CPC ser também "inovador" e "moderno", mas sempre com estrita observância do "due process of law". 


\section{a) $\mathrm{O}$ esboroamento gradativo da coesão sistêmica do antigo CPC/1973}

Faz ver a Comissão de Juristas, quando da apresentação da exposição de motivos que, em sua leitura, as incontáveis e seguidas alterações do CPC/1973 (antecipação de tutela, novo agravo, nova execução e cumprimento de sentença) enfraqueceram-lhe a coerência e comprometeram sua forma sistemática e, decorrentemente, a celeridade do processo, gerando o que designou "questões evitáveis", com a subtração indevida da atenção do operador do direito.

O objetivo declarado agora, pois, caminha no sentido de resgatar a "forma sistemática das normas processuais", com o intuito de obter-se "um grau mais intenso de funcionalidade".

b) Mantendo o que deve ser mantido

Outro aspecto levantado pelo projeto diz com seu anunciado "cuidado" na manutenção dos "institutos positivos" criados pelo CPC/1973. Apregoa, assim, não a ruptura com o passado, "mas um passo à frente".

O discurso visa afastar eventuais resistências, prometendo manter, do passado, o que se mostrar adequado aos novos desígnios do processo contemporâneo.

\section{OS 5 OBJETIVOS DA COMISSÃO}

Constam, da exposição apresentada pela Comissão de Juristas, cinco objetivos precípuos a orientar os trabalhos na feitura do novo CPC. São eles:

1 $^{\circ}$. estabelecer expressa e implicitamente verdadeira sintonia fina com a Constituição Federal;

$2^{\circ}$. criar condições para que o juiz possa proferir decisão de forma mais rente à realidade fática subjacente à causa;

$3^{\circ}$. simplificar, resolvendo problemas e reduzindo a complexidade de subsistemas como, por exemplo, o recursal; 
$4^{\text {o. }}$ dar todo o rendimento possível a cada processo em si mesmo considerado e,

$5^{\circ}$. finalmente, sendo talvez este último objetivo parcialmente alcançado pela realização daqueles mencionados antes, imprimir maior grau de organicidade ao sistema, dando-lhe mais coesão.

\section{O CPC E A CONSTITUIÇÃO FEDERAL}

$\mathrm{O}$ artigo $1^{\circ}$ do novo texto prevê que "O processo civil será ordenado, disciplinado e interpretado conforme as normas da Constituição da República Federativa do Brasil, observando-se, ainda, as disposições deste Código".

O artigo $6^{\circ}$, por sua vez, prevê que "ao aplicar o ordenamento jurídico, o juiz atenderá aos fins sociais e às exigências do bem comum, resguardando e promovendo a dignidade da pessoa humana e observando a proporcionalidade, a razoabilidade, a legalidade, a publicidade e a eficiência".

Portanto, doravante, deverá o processo ser ordenado, disciplinado e, principalmente, interpretado respeitando os valores e princípios fundamentais estatuídos na Carta da República. Não há confundir esta disposição com os "princípios do processo na Constituição Federal". Indica-os a maioria da doutrina brasileira: 1. coisa julgada (e seus desdobramentos), 2. devido processo legal, 3. princípio da isonomia, 4. do Juiz e do Promotor Natural, 5. da inafastabilidade do controle jurisdicional ou direito de ação, 6. do contraditório, 7. da ampla defesa, 8. da proibição da prova ilícita, 9. da publicidade, 10. do duplo grau de jurisdição, 11. da motivação das decisões judiciais e administrativas, 12. da presunção de não-culpabilidade, 13. da celeridade e 14. da duração razoável do processo. Tais questões encontram-se sedimentadas em doutrina e jurisprudência abundantes. O conteúdo do dispositivo estudado aponta para além disso. 
A dúvida que assalta, porém, é a definição do limite "interpretativo" que se dará ao tema. Assim, por exemplo, poderá Juiz ou Tribunal, em homenagem ao princípio da dignidade da pessoa humana e para fazer "justiça no caso concreto" (sic) ou, ainda, para efetivar "justiça material", elastecer prazo legal de admissibilidade de recurso (agravo, apelação)? Poderá, em face dos mesmos princípios, ainda que sem previsão legal sequer no Código de Defesa do Consumidor, inverter o ônus da prova ou, mais, aplicar a teoria da responsabilidade objetiva agravada?

Logo, declarou a Comissão de Juristas a expressa "constitucionalização" do processo civil determinando, por exemplo, noutro dispositivo, que o juiz, diante de matéria de ordem pública que fulmine o processo (prescrição, decadência etc.), em obediência ao princípio do contraditório, dê vistas à parte.

Preocupada com as constantes mudanças de orientação fornecida pelos julgados dos Tribunais Superiores (o que, de um lado, cria enorme instabilidade a todos os operadores do direito e perplexidades às partes $\mathrm{e}$, de outro, acarreta o desgaste do Poder Judiciário por não ser capaz de garantir um mínimo de "segurança jurídica") e, ainda, pelo impacto das demandas de massa (ou ações coletivas), quis a Comissão "criar estímulos", a partir da experiência das súmulas vinculantes (STF), "para que a jurisprudência se uniformize, à luz do que venham a decidir tribunais superiores e até de segundo grau, e se estabilize", "concretizando plenamente os princípios da legalidade e da isonomia".

\section{A DECISÃO JUDICIAL MAIS PRÓXIMA DA REALIDADE DA CAUSA}

No dizer da Comissão de Juristas, deve o processo ser convertido em "instrumento incluído no contexto social em que produzirá efeito o seu resultado" dando ênfase, para tanto, à resolução do conflito "pela via da mediação ou da conciliação" entendendo, neste sentido, "que a satisfação efetiva das partes pode dar-se de modo mais intenso se a solução é por elas criada e não imposta pelo juiz". A 
inspiração do tema colocado no novo código vem, confessadamente, da experiência alienígena na qual, inclusive, em algumas hipóteses exige-se, como requisito de admissibilidade da ação em juízo, a realização de anterior tentativa de conciliação extrajudicial. No novo CPC, a regra será a realização de audiência de conciliação prévia, com a determinação do comparecimento do réu, "sob pena de se qualificar sua ausência injustificada como ato atentatório à dignidade da justiça. Não se chegando a acordo, terá início o prazo para a contestação".

\section{SIMPLIFICAR, RESOLVER PROBLEMAS E REDUZIR A COMPLEXIDADE DE SUBSISTEMAS, INCLUSIVE O RECURSAL}

A partir de agora, a título de "simplificação" do sistema, poder-se-á deduzir a "reconvenção da reconvenção".

Muitos incidentes processuais foram extintos. Uniformizaram-se prazos recursais em sua quase totalidade. A "desconsideração da personalidade jurídica” foi inserida no corpo do texto e restou completamente sem sentido (veja-se, por exemplo, que deverá possuir os "pressupostos previstos em lei" (sic, art. 133).

Os procedimentos especiais foram, em larga medida, também extintos, mantendo-se a ação de consignação em pagamento, a ação de prestação de contas, a ação de divisão e demarcação de terras particulares, inventário e partilha, embargos de terceiro, habilitação, restauração de autos, homologação de penhor legal e ações possessórias.

Inaugura-se, também na senda das tutelas urgentes, a "tutela sumária". Assim, independentemente da existência do periculum in mora (mas desde que de juridicidade ostensiva), restando "evidente" o direito invocado/violado, possível o deferimento da tutela de evidência, ao lado da tutela de urgência, ambas passíveis de apreciação e concessão antes ou no curso do procedimento. 
Desapareceu o agravo retido. Todas as decisões anteriores à sentença poderão ser impugnadas na apelação. Restou mantido o agravo de instrumento para discussão, por exemplo, dentre outras hipóteses, acerca da concessão, ou não, das tutelas de urgência, sendo possível a sustentação oral quando da decisão de mérito (sic).

Mantém-se a interposição da apelação no $1^{\circ}$ grau, mas o juízo de admissibilidade passa a ser realizado diretamente pelo 2o grau de jurisdição.

Ainda no campo dos recursos, anuncia a Comissão "significativas alterações para o STJ e STF”.

\section{DAR TODO O RENDIMENTO POSSÍVEL A CADA PROCESSO EM SI MESMO CONSIDERADO}

O quarto objetivo da Comissão de Juristas foi permitir que cada processo "tenha o maior rendimento possivel". Assim, e por isso, "estendeu-se a autoridade da coisa julgada às questões prejudiciais”, deixando “a 'possibilidade jurídica do pedido' de ser condição da ação", julgando-se o pedido deduzido, nesta hipótese, improcedente, com resolução definitiva do feito [mérito]. Ainda, "criaram-se mecanismos para que, sendo a ação proposta com base em várias causas de pedir e sendo só uma levada em conta na decisão do $1^{\circ}$ e do $2^{\circ}$ grau, repetindo-se as decisões de procedência, caso o tribunal superior inverta a situação, retorne o processo ao $2^{\circ}$ grau, para que as demais sejam apreciadas, até que, afinal, sejam todas decididas e seja, efetivamente, posto fim à controvérsia".

Em igual medida, e inspirada no direito alienígena (sistemas italiano e francês - 'référré'), entendeu a Comissão adotar o que se designa "estabilização da tutela" (já algures referida).

$\mathrm{Na}$ contramão da propalada celeridade e simplificação processuais, prevê o artigo 955 que a apelação que tiver resultado não unânime, ao reformar sentença de mérito, "terá prosseguimento em sessão a ser designada com a presença de outros julgadores, a serem convocados (...) em número suficiente para 
garantir a possibilidade de inversão do resultado inicial (...) (sic)".

\section{IMPRIMIR MAIOR GRAU DE ORGANICIDADE AO SISTEMA, DANDO-LHE, ASSIM, MAIS COESÃO}

Neste último tópico, o tom maior reside na organização interna das regras e na sua harmonização. Assim, v.g., considera-se proposta a ação assim que protocolada a peça inaugural, definindo-se a prevenção pela distribuição da petição inicial. Também o litisconsórcio foi repaginado, a fim de desfazer, na linguagem da comissão, os "nós" que prendem o processo a injustificadas e arcaicas estruturas.

A ilogicidade e maltrato do vernáculo fica mais evidente quando assevera o novo anteprojeto que o litisconsórcio unitário poderá ser necessário ou facultativo para, logo após, afirmar que o litisconsórcio será necessário se unitário "ou por expressa disposição de lei" (arts. 114 e 115).

\section{NOSSA IMPRESSÃO A RESPEITO DO “NOVO” CPC}

A isenta e sincera leitura do texto do "novo" Código até aqui apresentado parece indicar ter ele se afastado, em vários momentos, de suas motivações originais, sendo muito pouco provável a percepção, na prática forense diária, da prometida celeridade/efetividade, menos ainda da resolução concreta de problemas. Tampouco se constata a propalada "simplificação do sistema", capaz de lhe proporcionar coesão suficiente a permitir centre o juiz sua atenção no mérito da causa.

Também não é possível inferir tenhamos nos livrado da disfuncionalidade sistêmica que envolvia o antigo CPC. Ainda, e pior, haverá novos focos de "estrangulamento" do processo, com o "travamento" do trâmite do feito e a necessidade de se retornar, em incontáveis hipóteses, à utilização do mandado de segurança para a garantia dos direitos fundamentais processuais 
dos litigantes (devido processo, ampla defesa e, principalmente, contraditório).

A deformação do anteprojeto em seu atual estágio chega ao ponto de não levar em consideração a natureza das ações, suas particularidades, enfim, culminando na determinação, ao juiz, para que atente obrigatoriamente à ordem cronológica de conclusão dos processos quando for proferir sentença ou acórdão, numa evidente inversão de valores, partindo do equivocado princípio da insinceridade e da desconfiança nos magistrados.

O "novo" texto, vezes várias, limitou-se a ser cópia fiel de inúmeros dispositivos do CPC que agora considera vetusto. Noutras tantas, optou por modificar levemente a forma, substituindo expressões consagradas no dia-a-dia forense por simples sinônimos, numa alteração nem sempre bem sucedida e invariavelmente desnecessária. Noutras, ainda, buscando talvez "simplificar" a linguagem, como sublinhado na apresentação, empobreceu-a, possivelmente querendo aproximar o "direito" do "povo", como se as pessoas comuns (não técnicas) pudessem abrir um Código desta magnitude e entendê-lo perfeitamente.

Ocorre que o empobrecimento da linguagem traz, em seu bojo, o esfacelamento do próprio direito que alega proteger, pois (re)cria dificuldades à aplicação de conceitos e institutos, reavivando polêmicas interpretativas com a utilização inadvertida de termos polissêmicos e dúbios, tudo em prejuízo da compreensão do direito e de sua aplicação final, que se continuará a prestar a destempo.

Não vemos real significado em várias das "inovações" nem nos parece, de igual forma, por exemplo, agredir aos princípios retores da Carta Maior o fato de o Magistrado extinguir o feito, de plano (sem oitiva de todos os interessados), verificando prescrita a pretensão autoral. Pelo contrário, a adoção da "nova regra" acarretará ainda maior e injustificado atraso na prestação jurisdicional. Na mesma esteira, pergunta-se qual a utilidade do julgamento parcial de mérito? Quais vantagens trará ao jurisdicionado? Valerá o sem-número de inconvenientes que 
fatalmente criará ao trâmite do feito (recursos os mais variados, inclusive o mandado de segurança)? Como interpretar utilmente dispositivo assim redigido: "Desde que possivvel, o órgão jurisdicional resolverá o mérito sempre que a decisão for favorável à parte a quem aproveitaria o pronunciamento que não o resolve."?

Utilizando-se da inteligência genuína e singular do Prof. Barbosa Moreira, refere nota da Comissão ser necessário "pôr na primeira instância o centro de gravidade do processo" (Breve notícia sobre a reforma do processo civil alemão. Revista de Processo. São Paulo, v. 28, n. 111, p. 103-112, jul./set. 2003, p. 105).

Com o merecido respeito, entretanto, é preciso consignar com franqueza que para que a justiça de primeiro grau opere eficazmente, não basta editar mais uma norma, por melhores que sejam as intenções de todos. A questão não é singela e merece reflexão profunda, passando inafastavelmente pelo redesenho do papel a ser desempenhado pelo Poder Judiciário numa sociedade complexa, pela reformulação dos concursos de ingresso (e permanência) no serviço público, pelas estruturas físicas e de pessoal dos fóruns, pelo repensar da inserção da tecnologia da informação no quotidiano forense, pelo resgate do respeito mútuo que se devem juízes, advogados, promotores de justiça e tribunais, pelo desempenho efetivo, dinâmico, proativo e menos punitivo das Corregedorias de Justiça e do CNJ, como forma de estancar o desprestígio corrosivo por que passa principalmente a magistratura da base, por exemplo.

De igual forma, em que pese alguns poucos dispositivos virem ao encontro de antigos anseios da advocacia, como o detalhamento de seus honorários e a redução de prazos processuais para manifestação do MP e Defensoria, e.g., como um todo, a atual versão do "novo" CPC representa não só mais uma oportunidade perdida, mas clamoroso retrocesso aos genuínos interesses da classe. Do que vale, por exemplo, suspender prazos processuais no período de final de ano e manter a continuidade dos trabalhos forenses? Com a redação do artigo 220 pretendem seus autores proibir o recesso de final de ano, desautorizando 
CNJ e Tribunais? Qual a utilidade dessa visão revanchista e pequena para o jurisdicionado? O que acontecerá, na verdade, é que os cartórios simplesmente represarão o trabalho e, findo o prazo de suspensão, farão publicar todas as relações de intimação duma só vez, inviabilizando o cumprimento dos despachos, interlocutórias e sentenças pelo advogado.

A fundamentação utilizada para a inserção de vários dispositivos do "novo" CPC mostra-se altamente conflitante, o que transparece da sua simples e desapaixonada leitura.

Assim, inconciliável se apresenta o contido nos parágrafos acima (centrar o foco do processo no juiz de primeiro grau), com o afirmar que "o desvirtuamento da liberdade conferida ao juiz de decidir com base em seu entendimento sobre o sentido real da norma implicou no comprometimento do princípio da "isonomia"”. Conseguirá o "novo" Código, com essa postura, "pôr os juizes da primeira instância no centro de gravidade do processo"?

A fim de justificar o engessamento da criação judicial na base (criação esta a mais saudável, pois permite inclusive a oxigenação do entendimento dos Tribunais Superiores, posto que os juízes brasileiros ainda possuem a tríplice garantia - vitalícios, inamovíveis, sem redução nominal de vencimentos -, o que lhes confere liberdade ideológica e política, vez que desvinculados dos favores do poder), forjou-se o "incidente de julgamento conjunto de demandas repetitivas" sustentando que, "uma vez firmada jurisprudência em certo sentido, esta deve, como norma, ser mantida, salvo se houver relevantes razóes recomendando sua alteração". Explicitou assim, o "novo" CPC, acreditando com isso inibir a multiplicidade de decisões sobre um mesmo tema, que "a mudança de entendimento sedimentado observará a necessidade de fundamentação adequada e específica, considerando o imperativo de estabilidade das relações jurídicas" para, ao depois, estabelecer que "na hipótese de alteração da jurisprudência dominante do STF e dos Tribunais Superiores, ou oriunda de julgamentos de casos repetitivos, pode haver modulação dos efeitos da alteração no interesse social e no da segurança jurídica". 
Como se vê, continuamos à mercê dos ventos. Não há limite algum para que a alteração jurisprudencial ocorra ao sabor dos entendimentos do dia, desde que "fundamentada" (e poderia ser diferente, sem agressão ao comando do artigo 93, inciso IX, da Constituição Federal?). Mais ainda, e aí estiolando os princípios da "legalidade" e "isonomia" que inspiraram o dispositivo central, permitiu-se a "modulação dos efeitos da alteração no interesse social e no da segurança jurídica”, como hoje já se verifica, a.e., quando do julgamento de questões envolvendo a cobrança ilegal de tributos pelo Estado e sua tormentosa devolução (vide artigo 27 da Lei no 9868/1999).

Com o inegável intuito de "revogar" sólida jurisprudência dos Tribunais Superiores, a nova versão do anteprojeto prevê a obrigatoriedade de a sentença enfrentar "todos os argumentos deduzidos no processo capazes de, em tese, infirmar a conclusão adotada pelo julgador”. Todos os argumentos? Em tese? Ora!

E ainda, na esteira do grosseiro "engessamento" e "desoxigenação" da jurisprudência, determina-se a invalidade de sentença que "deixar de seguir enunciado de súmula, jurisprudência ou precedente invocado pela parte, sem demonstrar a existência de distinção no caso em julgamento ou a superação do entendimento". É o fim do livre e sério convencimento do magistrado. Petições e contestações "quilométricas”, contendo pedidos quase infinitos e muitas vezes desprovidos de seriedade, exigirão sentenças igualmente enormes e, claro, cada vez mais escassas!

No que se refere à condução interna do feito, com a obrigatoriedade (como regra) de prévia audiência conciliatória em todas as hipóteses, andou muito mal o Código. Sem estrutura adequada (física, financeira, de pessoal), encheremos as já abarrotadas pautas de julgamento/conciliação dos juízes de primeiro grau (aqueles que serão o "centro gravitacional do novo processo", lembra?), retardando o julgamento das causas, em clamoroso prejuízo da celeridade processual. A experiência mostra quão pouco eficaz é a tentativa de conciliar as partes, v.g., 
em feitos que envolvam questões bancárias, as teles, seguradoras e temas relacionados a danos anímicos e estéticos. Por razões até de estrutura societária, muitas das empresas envolvidas em demandas tais só podem efetuar pagamento ou proposta de acordo após a prolação da sentença.

No tópico, para maior desprestígio dos advogados, oneração das partes, dos cofres públicos e atraso na prestação jurisdicional, serão os tribunais obrigados a criar "centros judiciários de solução consensual de conflitos”. A ausência de técnica e qualidade redacionais acabou por dizer mais que o óbvio, i.e., que na conciliação é "vedada a utilização de qualquer tipo de constrangimento ou intimidação para que as partes conciliem”. Por acaso, em algum outro momento ou ato processual são permitidos o constrangimento ou a intimidação?

Também inconcebível conste num Código que se quer moderno e atual, como se de inovação de ponta se tratasse, artigo que trate do "assessoramento direto do juiz por um ou mais servidores".

Ainda, a advertência ao réu acerca da aplicação de "pena por ato atentatório à dignidade da justiça” em razão de seu não comparecimento à audiência prévia de tentativa de conciliação só aumentará a animosidade entre as partes e servirá de "moeda de troca ao autor”, que poderá assumir, dependendo do caso, posição de "ataque/intransigência", colocando-se em situação de vantagem desmedida em face do réu.

Então, porque não manter as disposições atuais do CPC/1973, permitindo ao Magistrado, a qualquer tempo, verificando a possibilidade de acordo, designar audiência para tal fim (artigo 125, inciso IV, do CPC), sem prejuízo à parte que não comparecer? Porque voltarmos à punição severa pelo não comparecimento em audiência de simples tentativa conciliatória?

Em suma, as mais das vezes, esta audiência será inútil e consumirá indevidamente precioso tempo dos juízes, advogados e principalmente das partes. 
Inegável o olhar mais do que atento dispensado pelo projeto aos "recursos" apresentando-se o tema, claramente, como um dos pilares da reforma empreendida, o que consumiu boa parte do tempo das discussões ali travadas, como se conclui já da apresentação do "novo" texto, ao se colocar, exemplificativamente, as seguintes perguntas: Como vencer o volume de ações e recursos gerado por uma litigiosidade desenfreada, máxime num país cujo ideário da nação abre as portas do judiciário para a cidadania ao dispor-se a analisar toda lesão ou ameaça a direito? Como desincumbir-se da prestação da justiça em um prazo razoável diante de um processo prenhe de solenidades e recursos?

\section{CONCLUSÃO}

Reformas legislativas de fôlego, como o é a introdução de um "novo" CPC no país, deveriam recuperar o Estado para a sociedade. Este projeto, definitivamente, não o faz!

O que se percebe sem esforços, porém, é que o "novo" CPC preocupou-se demasiado com questiúnculas e não será capaz, também por isso, de responder aos angustiantes e gigantescos problemas que pululam nos abarrotados fóruns do país inteiro, introduzindo um modelo academicista que se sustenta no atraso perverso, no qual o futuro financia o passado.

É uma enorme lástima que desperdicemos oportunidades tão raras.

Abstract: Is pending in Congress the project the
'new' CPC in its umpteenth version. But when his
initial presentation, at the Senate, showed up the
text lacks meaning and direction. Now, "muti-
lated" and "grafted" on all sides, dehydrated as
a result of long political negotiation, hostage of
chance and carelessness, it boils down to a few
advances and so many unexplained setbacks.
In this brief reflection, we present the structure of
the initial project of the "new" CPC, the main moti-
vations (guidelines) used for the initial commission 
formed at the Senate, the five objectives listed for it, the dialogue between the Federal Constitution and the Code of Civil Procedure for then punctuate their most serious problems from the perspective of those who operate in the daily "f'orum" as Judge and as a Lawyer, concluding that it is a rare opportunity missed.

Keywords: New CPC. Reform. Dysfunctionality. Anachronism. Wasted opportunity.

\section{REFERÊNCIAS}

BRASIL. Projeto de Lei n. 8.046/2010.

BRASIL. Lei No 5.869 de 11 de Janeiro de 1973. Código de Processo Civil, 2013.

REVISTA DE PROCESSO. São Paulo, v. 28, n. 111. jul./set. 2003. 